\title{
Orbital and Medial Prefrontal Cortex Functional Connectivity of Major Depression Vulnerability and Disease
}

Citation for published version (APA):

Samara, Z., Evers, E. A. T., Peeters, F., Uylings, H. B. M., Rajkowska, G., Ramaekers, J. G., \& Stiers, P. (2018). Orbital and Medial Prefrontal Cortex Functional Connectivity of Major Depression Vulnerability and Disease. Biological Psychiatry: Cognitive Neuroscience and Neuroimaging, 3(4), 348-357.

https://doi.org/10.1016/j.bpsc.2018.01.004

Document status and date:

Published: 01/04/2018

DOI:

10.1016/j.bpsc.2018.01.004

Document Version:

Publisher's PDF, also known as Version of record

Document license:

Taverne

Please check the document version of this publication:

- A submitted manuscript is the version of the article upon submission and before peer-review. There can be important differences between the submitted version and the official published version of record.

People interested in the research are advised to contact the author for the final version of the publication, or visit the DOI to the publisher's website.

- The final author version and the galley proof are versions of the publication after peer review.

- The final published version features the final layout of the paper including the volume, issue and page numbers.

Link to publication

\footnotetext{
General rights rights.

- You may freely distribute the URL identifying the publication in the public portal. please follow below link for the End User Agreement:

www.umlib.nl/taverne-license

Take down policy

If you believe that this document breaches copyright please contact us at:

repository@maastrichtuniversity.nl

providing details and we will investigate your claim.
}

Copyright and moral rights for the publications made accessible in the public portal are retained by the authors and/or other copyright owners and it is a condition of accessing publications that users recognise and abide by the legal requirements associated with these

- Users may download and print one copy of any publication from the public portal for the purpose of private study or research.

- You may not further distribute the material or use it for any profit-making activity or commercial gain

If the publication is distributed under the terms of Article $25 \mathrm{fa}$ of the Dutch Copyright Act, indicated by the "Taverne" license above, 


\title{
Orbital and Medial Prefrontal Cortex Functional Connectivity of Major Depression Vulnerability and Disease
}

\author{
Zoe Samara, Elisabeth A.T. Evers, Frenk Peeters, Harry B.M. Uylings, Grazyna Rajkowska, \\ Johannes G. Ramaekers, and Peter Stiers
}

\begin{abstract}
BACKGROUND: Pathophysiology models of major depression (MD) center on the dysfunction of various cortical areas within the orbital and medial prefrontal cortex. While independent structural and functional abnormalities in these areas are consistent findings in $\mathrm{MD}$, the complex interactions among them and the rest of the cortex remain largely unexplored.

METHODS: We used resting-state functional magnetic resonance imaging connectivity to systematically map alterations in the communication between orbital and medial prefrontal cortex fields and the rest of the brain in MD. Functional connectivity (FC) maps from participants with current MD $(n=35)$, unaffected first-degree relatives $(n=36)$, and healthy control subjects $(n=38)$ were subjected to conjunction analyses to distinguish FC markers of MD vulnerability and FC markers of MD disease.

RESULTS: FC abnormalities in MD vulnerability were found for dorsal medial wall regions and the anterior insula and concerned altered communication of these areas with the inferior parietal cortex and dorsal posterior cingulate, occipital areas and the brainstem. FC aberrations in current MD included the anterior insula, rostral and dorsal anterior cingulate cortex, and lateral orbitofrontal areas and concerned altered communication with the dorsal striatum, the cerebellum, the precuneus, the anterior prefrontal cortex, somatomotor cortex, dorsolateral prefrontal cortex, and visual areas in the occipital and inferior temporal lobes.

CONCLUSIONS: Functionally delineated parcellation maps can be used to identify putative connectivity markers in extended cortical regions such as the orbital and medial prefrontal cortex. The anterior insula and the rostral anterior cingulate cortex play a central role in the pathophysiology of MD, being consistently implicated both in the MD vulnerability and MD disease states.
\end{abstract}

Keywords: Family history, Functional connectivity, Major depression, MRI, Prefrontal, Vulnerability

https://doi.org/10.1016/j.bpsc.2018.01.004

Major depression (MD) is a debilitating syndrome presenting with various symptoms in mood, reward, and decision making (1). The efficacy of MD neuromodulation therapies such as transcranial magnetic stimulation (2) and deep brain stimulation (3) with various targets demonstrates in a "proof of concept" manner that $\mathrm{MD}$ is a systems-level disorder involving a complex pattern of altered interactions between several brain areas. Convergent neuroimaging findings suggest that, together with limbic and autonomic centers, subregions within the orbital and medial prefrontal cortex (OMPFC) (4-6) play a central role in MD's aberrant networks. Understanding of the neurocircuitry pathways underlying MD symptoms and treatment response remains elusive, despite the large body of evidence documenting abnormalities in various OMPFC subregions and the efficacy of connectivity-based treatments with OMPFC targets.

The elucidation of MD-related changes, if any, in the functional wiring between the OMPFC subregions and key brain areas for autonomic, cognitive, and affective control is critical for generating new hypotheses on MD disease mechanisms and for identifying connectivity biomarkers to guide diagnosis and treatment. On the theoretical side, neurocircuit models of MD propose altered pathways based only on tracer or lesion findings in animals and rare postmortem human reports (7). Thus far, magnetic resonance imaging (MRI) studies of MD have examined functional wiring of the OMPFC for select coordinates derived from activation studies, either as part of the anterior default mode network or coarsely with predefined general anatomical labels [see (8-11) and reviews in (12,13)].

Recent neuroimaging advances on MRI connectivity analysis tools enable us to study the cortical organization systematically for a specified area or the cerebral cortex as a whole [see review in (14)]. These tools use homogeneity in functional connectivity (FC) in an attempt to delineate cortical fields, which are anatomically defined as architectonic and 
connectional homogeneous patches of cortex $(15,16)$. While it is still undetermined how these fields correspond to anatomically defined cytoarchitectonic areas, at the group level these data-driven methods yield a systematic parcellation of cortex in subregions (17) that are neuroanatomically plausible in general terms of location, spatial extend, and whole brain FC $(14,18-24)$.

In the current study, we make use of such a parcellation of the OMPFC in the left hemisphere of 34 healthy adults. That study delineated 19 functional subregions in the left hemisphere cortex covering the anterior medial PFC, orbital surface, and ventral anterior insula (white outlines in Figures 1-3). Their spatial organization and intrinsic cortical and subcortical FC characteristics were generally in accordance with current knowledge of the anatomical organization of this part of the cerebral cortex from cytoarchitectonic and tracer studies in the macaque monkey and cytoarchitectonic and diffusion MRI studies in humans [for a detailed discussion see Samara et al. (17) and their Supplement]. Here, we used this parcellation map as a layout to identify FC changes associated with OMPFC in MD.

We focused on the left OMPFC because only this hemisphere was extensively studied (17). Pathophysiology studies of MD and repetitive transcranial magnetic stimulation interventions (i.e., excitatory left dorsolateral PFC vs. inhibitory right) in patients with MD suggest that left and right PFC might be differentially involved, while transcranial magnetic stimulation treatment centered on the left dorsolateral PFC is the most widely used (25). We sought specifically to test the hypotheses that OMPFC subregions show altered connectivity patterns that are 1) common to MD patients and at-risk individuals compared to healthy control subjects (connectivity markers of MD vulnerability) and 2) unique to the MD group compared with at-risk individuals and control subjects (connectivity markers of acute MD or MD disease). With this design, we aimed to uncover FC abnormalities that might confer susceptibility to MD by giving rise to emotional and cognitive symptoms observed in unaffected at-familial MD risk individuals and in MD patients in remission. At the same time, we specifically aimed to dissociate these abnormalities from the FC aberrations that characterize the acute MD state and that may underlie the cognitive, affective, and somatic symptoms observed during depressive episodes.

\section{METHODS AND MATERIALS}

\section{Clinical Assessments}

Thirty-five participants experiencing a major depressive episode (cutoff Beck Depression Inventory-II score >20; mean age \pm SD, $38.9 \pm 11.6$ years; $71 \%$ female) (MD group), 36 unaffected first-degree relatives (mean age \pm $\mathrm{SD}, 34 \pm 14.6$ years; $72 \%$ female) (family history [FH] group), and 38 nonpsychiatric control subjects (mean age $\pm \mathrm{SD}, 36 \pm 16.4$ years; $68 \%$ female) (healthy control [HC] group) participated after providing informed consent. $\mathrm{Pa}-$ tients were included if they met DSM-IV-TR criteria for MD and excluded if they were diagnosed with bipolar disorder I or II or substance dependence or were taking benzodiazepines. Participants in the other two groups were excluded in the presence of any Axis I diagnosis. Screening procedures and diagnostic and medication histories are reported in the Supplement. The study was approved by the Medical
Ethical Committee of Maastricht University. Participants completed the Beck Depression Inventory-II, the Brief Symptom Inventory, and the Quick Inventory of Depressive Symptomatology Self-Report (26-28). They also completed Raven's Standard Progressive Matrices, a 60 -item test of nonverbal IQ (29).

\section{MRI Acquisition and Preprocessing}

MRI data included a resting state scan of minimally $6.4 \mathrm{mi}-$ nutes (repetition time $=2.5$ seconds, $2 \times 2 \times 3 \mathrm{~mm}$ voxels, 153 or 203 volumes, equally spread across the three groups), a high-resolution T1-weighted anatomical scan, and a field map. The echo-planar imaging sequence was optimized to reduce susceptibility artifacts in the orbital cortex: low echo time (25 $\mathrm{ms})$, thinner slices $(2 \mathrm{~mm})$ oriented with the orbital surface $\left( \pm 30^{\circ}\right)$, and field map distortion correction [see Samara et al. (17) for quantifications and discussion of the orbital signal quality with this sequence and scanner]. Data preprocessing with SPM 5 software (Wellcome Trust Centre for Neuroimaging, London, UK) included correction for slice timing, head motion, and spatial distortion; normalization to the Montreal Neurological Institute 152 template; 6-mm full width at half maximum smoothing; removal of linear trends, white matter, cerebrospinal fluid signals, and affine head motion parameters; and finally 0.1 to $0.01 \mathrm{~Hz}$ bandpass filtering. To further eliminate detrimental effects of head motion $(30,31)$, volumes with a framewise displacement exceeding $10 \%$ of the slice thickness were removed and groups were equated on the mean framewise displacement $(p=.57)$. Acquisition parameters and preprocessing are detailed in the Supplement.

\section{Statistical Analyses}

We sought to identify FC abnormalities in 19 OMPFC fields of the left hemisphere parcellation map (17). For ease of comprehension, we refer to these fields by their presumed anatomical interpretations, as discussed in Samara et al. (17). The locations of the fields are indicated as outlines in Figures 1, 2, and 3 [for details, see Samara et al. (17)]. A set of 19 seed time courses was created for each participant by selecting voxels within a sphere of a $4-\mathrm{mm}$ radius around the center of mass of each field. The focus on the field centers ensured that only voxels that were representative of each field's functional dynamic were included, despite individual variation in the exact location of the fields in each individual data set. To further increase the field specificity of the connectivity profiles, we computed for each field the first Eigen vector of the low frequency $(0.01-0.1 \mathrm{~Hz})$ signal in the time courses of the selected voxels. Per seed, whole-brain FC profiles were calculated as the Fisher $Z$ transformed Pearson's correlation between each seed's time course and the time course of each voxel in that participant's brain. These fieldand participant-specific FC maps were subjected to a random effects general linear model analysis to estimate differences between the three groups, with age, gender, and IQ Raven score as covariates.

To test for connectivity abnormalities of MD vulnerability, we created conjunction maps of the $F$ contrasts between 1) the $\mathrm{HC}$ and the MD groups and 2) the $\mathrm{HC}$ and the $\mathrm{FH}$ groups. These maps highlighted voxels whose FC with the seed differed both between control subjects and patients and 
between control subjects and at-risk participants. Further, to ensure in our vulnerability measure that $\mathrm{FH}$ participants were not different from MD patients, we removed from the conjunction maps all voxels significant at a lenient threshold (.001 uncorrected) in the $\mathrm{F}$ contrast between MD versus $\mathrm{FH}$ groups. This eliminated as markers of vulnerability all voxels in which the FC change in the at-risk participants was intermediate between the HCs and the MD patients.

To test for connectivity abnormalities associated with acute $\mathrm{MD}$, we created new conjunction maps, now of the $\mathrm{F}$ contrasts between 1) the MD and $\mathrm{HC}$ groups and 2) the $\mathrm{MD}$ and $\mathrm{FH}$ groups. These conjunction maps now highlighted voxels whose FC with the seed differed both between MD patients and control subjects and between patients and at-risk participants. Further, to ensure in our disease manifestation measure that atrisk participants were not different from the HCs, we removed from the conjunction maps all voxels significant at a lenient threshold (.001 uncorrected) in the $\mathrm{F}$ contrast between $\mathrm{FH}$ versus $\mathrm{HC}$. This excluded all voxels with an FC change in the atrisk participants that was intermediate between the $\mathrm{HCs}$ and the MD patients so that the final maps contained voxels whose FC was exclusively altered in the disease state.

All conjunction maps were tested for significance with Monte Carlo simulations $(10,000$ iterations; voxel level $p=.01$, cluster level $p=.0025$, Bonferroni-adjusted for 19 independent comparisons). We ensured that the connectivity differences reported here were not driven by antidepressant medication use or comorbidity (MD group) or self-reported symptoms (both depression and other psychiatric complaints in the $\mathrm{FH}$ group) by regressing the influence of these variables from the $\mathrm{MD}$ and $\mathrm{FH}$ individual maps before the final across-groups analysis and using the residual cleaned maps for these groups in the next step. Gray matter differences between the three groups were controlled by removing from our results maps all voxels which their probability of being gray matter was significantly different (.001 uncorrected) among the groups.

We determined the direction of FC differences in MD vulnerability and in disease manifestation with region of interest-based pairwise $t$ tests using the $r$ to $Z$ transformed values in the conjunction maps. Correlation analyses for the MD group between the FC changes in the acute phase and our clinical measures were also performed (details of all analyses can be found in the Supplement).

\section{RESULTS}

\section{Demographic and Clinical Characteristics}

MD patients had their first episode on average at 29.3 years of age $(S D=11.4$ years $)$ and had a mean of 2.9 episodes $(S D=3$

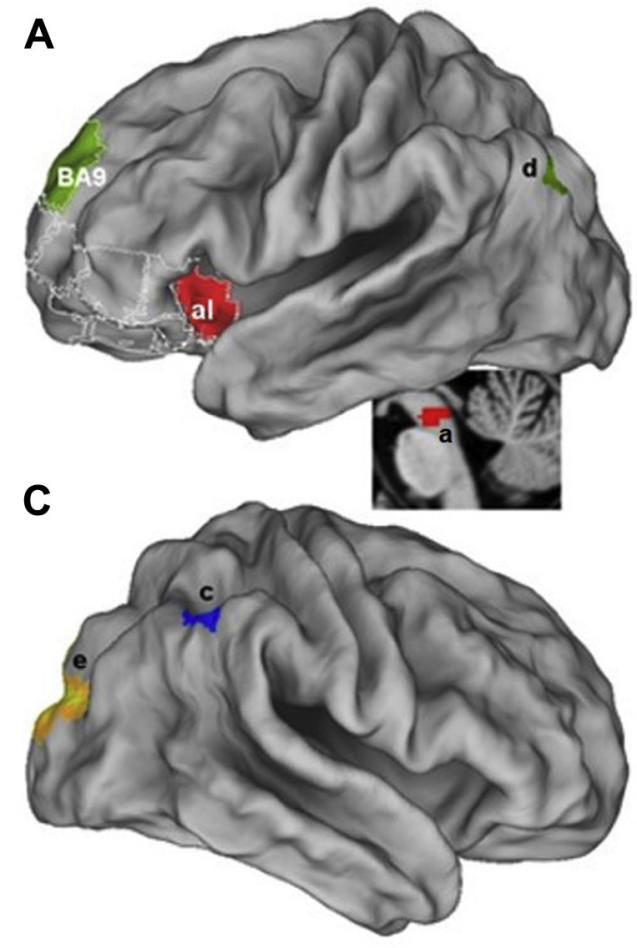

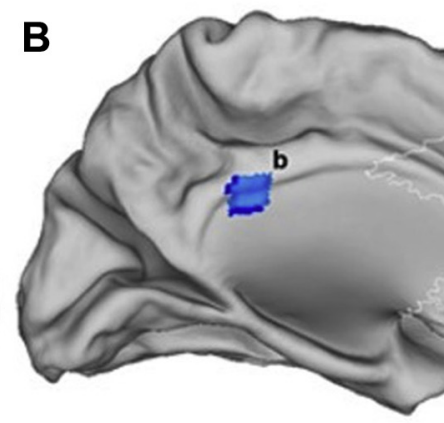

D

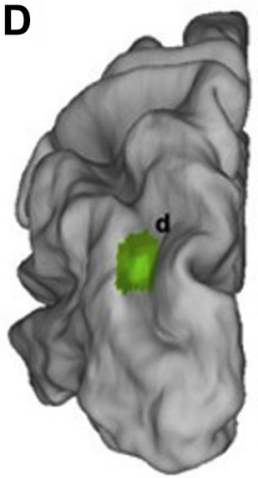

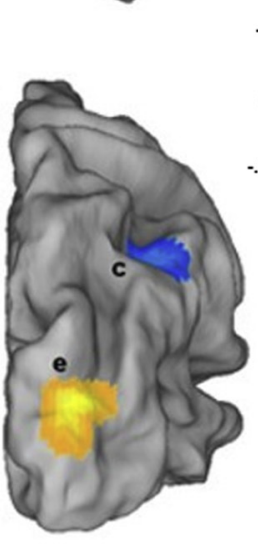
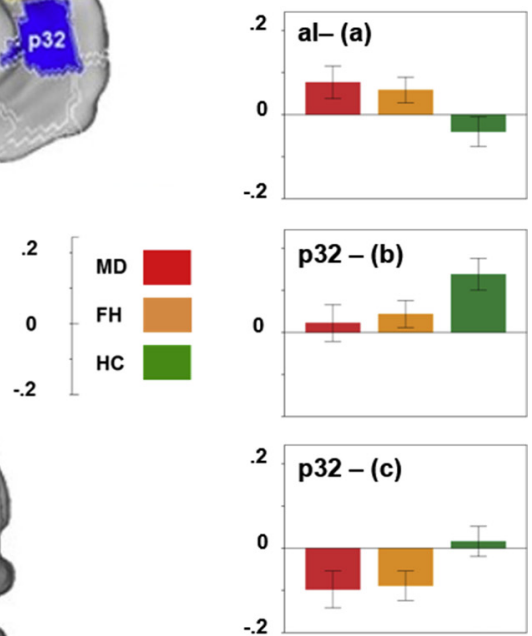

Figure 1. Functional connectivity changes associated with major depression (MD) vulnerability. Region nomenclature corresponds to Samara et al. (17). Voxel clusters of MD vulnerability-related functional connectivity changes (MD, at-risk family history group [FH] $\neq$ healthy control subjects [HC]) are colored in the same color as the region that provided the seed for the functional connectivity map. (A) Lateral view of the left hemisphere. (B) Medial view of the left hemisphere. (C) Lateral view of the right hemisphere. (D) Posterior view of both hemispheres. (E) Bar plots showing connectivity strength (Z[r]) in the three groups for the anterior insula (al) and the rostral perigenual cingulate (p32) (see Supplement for all plots). Error bars represent $95 \%$ confidence intervals. a, periaqueductal gray; b, posterior cingulate cortex; BA, Brodmann area; c, dorsal inferior parietal cortex; d, intraparietal sulcus; d32, paracingulate region 32 dorsal; e, intraparietal sulcus/occipital. 
A

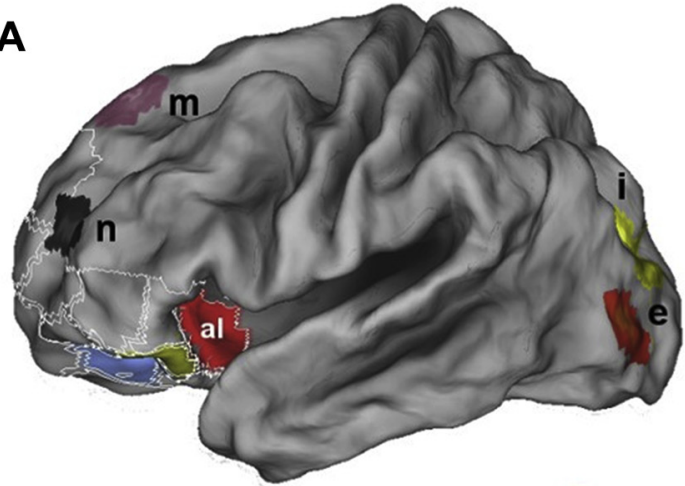

D

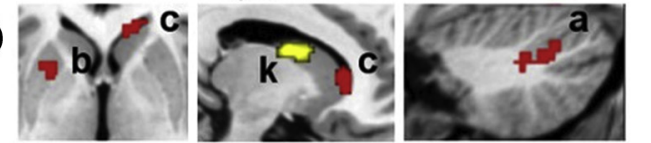

E

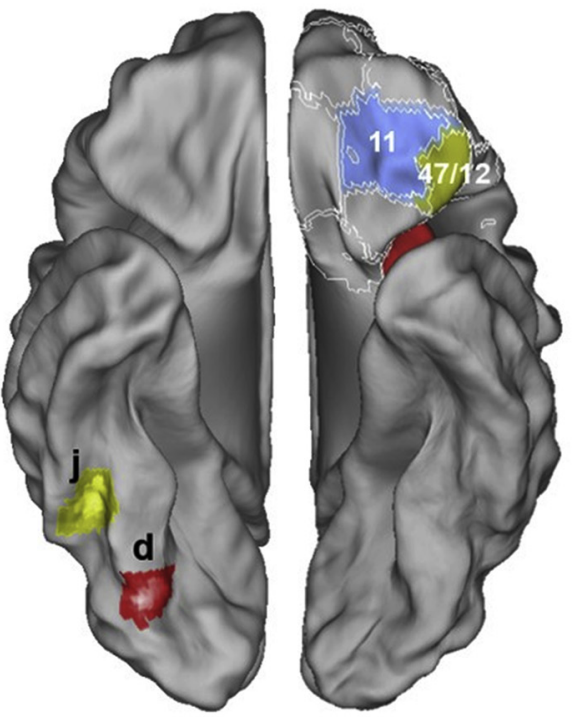

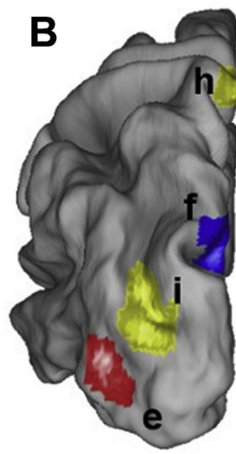

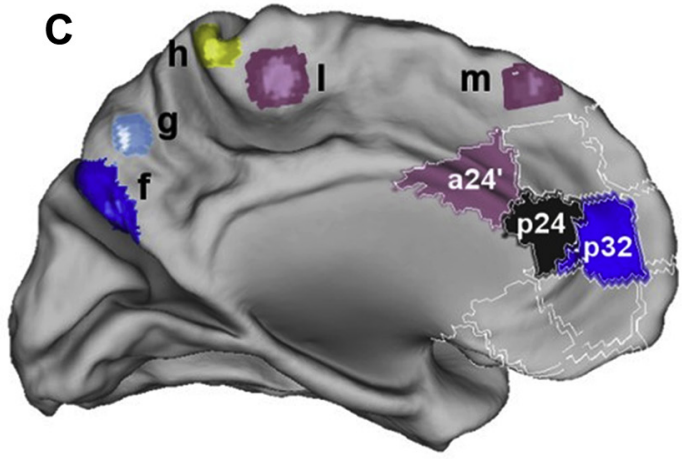

F
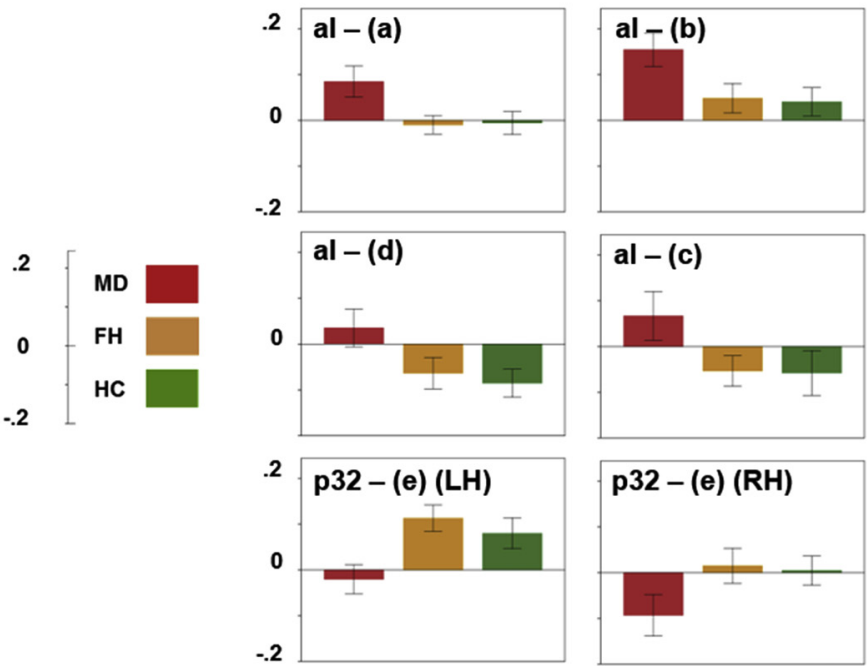

Figure 2. Functional connectivity abnormalities of major depression (MD) disease. Region nomenclature corresponds to Samara et al. (17). Voxel clusters of $\mathrm{MD}$ disease-related functional connectivity changes $(\mathrm{MD} \neq$ at-risk family history group $[\mathrm{FH}]$, healthy control subjects $[\mathrm{HC}])$ are color-coded according to the orbital or medial region that provided the seed for the functional connectivity map. (A) Lateral view of the left hemisphere (LH). (B) Posterior dorsal view of the left hemisphere. (C) Medial view of the left hemisphere. (D) Slices through the cerebellum and basal ganglia to show cluster of altered connectivity with the anterior insula (al) region and the lateral orbital 47/12 region. (D) Ventral view of both hemispheres. (E) Ventral view of both hemispheres. (F) Bar plots showing connectivity strength $(Z[r])$ in the three groups for the anterior insula and the rostral perigenual cingulate region 32 (p32) (see Supplement for all plots). Error bars represent $95 \%$ confidence intervals. a, cerebellum; a24', midcingulate field a24; b, putamen; c, caudate; $d$, fusiform; e, occipital; f, precuneus; g, precuneus; h, paracentral lobule; i, occipital; j, inferior temporal; k, caudate body; I, paracentral lobule; m, dorsolateral prefrontal cortex; n, superior frontal gyrus; p24, rostral perigenual cingulate region 24; $\mathrm{RH}$, right hemisphere.

episodes). Comorbidity (having at least one additional Axis I diagnosis), and the use of antidepressants at the time of the scan was reported by $51 \%$ and $48 \%$ of the MD group, respectively. The most prevalent comorbid diagnosis was social phobia, and most participants were taking selective serotonin reuptake inhibitors (Supplemental Table S1). Average Beck Depression Inventory-II and Quick Inventory of Depressive Symptomatology Self-Report scores at the time of the scan in the MD group were 32.74 and 16.57, respectively. Atrisk participants had clinically and statistically significantly lower scores of depressive and general psychiatric symptomatology compared with the MD group (Table 1). Their symptom scores were somewhat elevated compared with $\mathrm{HCs}$ (Table 1), but none scored near the cutoff for clinical symptomatology. Groups were matched in age, gender, and IQ (all $p$ values $>.2)$.

\section{Neuroimaging Analysis}

FC Abnormalities of MD Vulnerability. In our analysis for markers of MD vulnerability we found that MD patients and at-risk individuals share various FC abnormalities in the OMPFC compared with control subjects. The general linear model analysis revealed changes in the FC of four OMPFC regions: the 

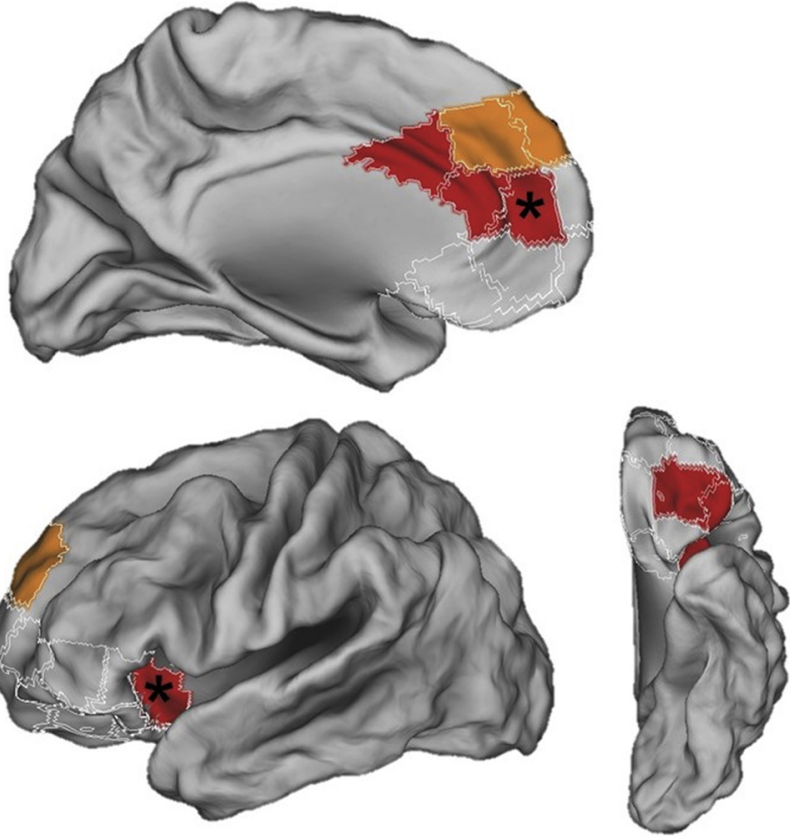

Figure 3. Summary representation of all connectivity findings. Regions in orange were found to have altered functional connectivity in major depression vulnerability, while regions in red were found to have altered functional connectivity in the acute major depression phase. The anterior insula and the rostral cingulate (marked with asterisks) were found to have changed connectivity with various areas in the rest of the cortex both in major depression vulnerability and during depressive episodes.

anterior insula, the paracingulate regions 32 pregenual (p32) and 32 dorsal (d32) [see (20) for area homology, nomenclature, and relevant references], and the dorsomedial frontal Brodmann area 9 (BA 9) (Figure 1). Region of interest-based post hoc analysis indicated that MD vulnerability is characterized by decreased coupling between BA 9 and an area of the ventral intraparietal sulcus and between area p32 and the dorsal posterior cingulate and contralateral inferior parietal cortex (see Table 2 for $p$ values of post hoc tests). In contrast, increased FC was observed between the anterior insula and the brainstem and between medial region d32 and the contralateral dorsal occipital cortex. It should be noted that in MD vulnerability no significant changes in the functional coupling among any of the 19 OMPFC fields with each other were observed.

FC Abnormalities of MD Disease. In our analysis for aberrations in MD disease, we found that MD patients, in addition to the FC changes that they share with the at-risk group, also show unique impairments in the communication of the OMPFC with several other brain areas in the rest of the cortex. The random effects general linear model analyses revealed additional changes for six OMPFC fields, summarized in Figure 2 and Table 2. Two of the OMPFC fields implicated in vulnerability also show abnormalities associated with MD disease: the anterior insula and the dorsomedial prefrontal cortex (p32). The anterior insula had changed coupling ipsilaterally with the lateral occipital cortex, fusiform gyrus, cerebellum, and putamen, and contralaterally with the caudate nucleus. Field p32 had altered coupling with the ipsilateral precuneus. Four additional fields had changed functional coupling in MD patients compared with the other two groups. On the medial side, p24 had changed coupling with the anterior superior frontal gyrus (SFG), while midcingulate field a24' had changed coupling with the dorsolateral PFC and the left paracentral lobule. At the orbital side, changed coupling was found between lateral orbital area $47 / 12$ and the dorsal occipital cortex bilaterally, the left inferior temporal lobe and the parietal paracentral lobule, and subcortically with the contralateral body of the caudate nucleus. Also, central orbital area 11 had changed coupling with the dorsal precuneus. Region of interest-based post hoc analysis indicated that MD patients had decreased FC between area p32 and the precuneus compared with both at-risk individuals and control subjects. In contrast, the MD group had increased FC compared to the other two groups between all the other OMPFC cortical fields and the cortical and subcortical regions reported. Similar to the MD vulnerability results, no functional coupling changes between the 19 OMPFC fields were observed in this analysis.

Table 1. Sample Characteristics and Clinical Measures

\begin{tabular}{|c|c|c|c|c|c|c|c|c|c|}
\hline \multirow[b]{3}{*}{ BDI-II } & \multicolumn{2}{|c|}{ MD } & \multicolumn{2}{|c|}{$\mathrm{FH}$} & \multicolumn{2}{|c|}{$\mathrm{HC}$} & \multirow[b]{2}{*}{$F_{2,106}$} & \multirow{2}{*}{\multicolumn{2}{|c|}{$p$ Value }} \\
\hline & Mean & $\mathrm{SD}$ & Mean & SD & Mean & SD & & & \\
\hline & 32.74 & 7.66 & 5.78 & 5.04 & 2.24 & 2.97 & 328.68 & $.000^{a}$ & $.020^{b}$ \\
\hline BSI GSI & 1.67 & 0.55 & 0.34 & 0.38 & 0.14 & 0.17 & 159.24 & $.000^{a}$ & .098 \\
\hline BSI PST & 38.66 & 7.67 & 12.42 & 10.16 & 6.5 & 7.27 & 147.18 & $.000^{a}$ & $.010^{b}$ \\
\hline BSI PSDI & 2.26 & 0.46 & 1.18 & 0.39 & 0.89 & 0.41 & 108.07 & $.000^{a}$ & $.009^{b}$ \\
\hline QIDS & 16.57 & 3.38 & 3.91 & 3.46 & 2.1 & 1.84 & 252.58 & $.000^{a}$ & $.030^{b}$ \\
\hline Age, Years & 38.88 & 11.8 & 34.03 & 14.77 & 36.21 & 16.65 & 0.98 & .377 & - \\
\hline Female, \% & 71 & - & 72 & - & 68 & - & $\chi_{(2)}^{2}=0.14$ & .930 & - \\
\hline Raven IQ & 45.2 & 8.99 & 48.28 & 6.5 & 46.03 & 7.46 & 1.53 & .221 & - \\
\hline
\end{tabular}

BDI-II, Beck Depression Inventory-II; BSI, Brief Symptom Inventory; FH, at-risk family history group; GSI, global severity index; HC, healthy control subjects; MD, major depression group; PSDI, positive symptom distress index; PST, positive symptom total; QIDS, Quick Inventory of Depressive Symptomatology.

${ }^{a}$ The MD group differs significantly from relatives and control subjects in the $F$ test.

${ }^{b}$ The $\mathrm{FH}$ group differs significantly from control subjects in post hoc comparisons. In the post hoc tests between MD vs. $\mathrm{HC}$ and MD vs. FH , al post hoc $p$ values are $<.000$. 
Table 2. Summary of Magnetic Resonance Imaging Results

\begin{tabular}{|c|c|c|c|c|}
\hline OMPFC Area & Anatomy & Average MNI & Voxel Extent & $p$ Value \\
\hline \multicolumn{5}{|l|}{ MD Vulnerability } \\
\hline al & Brainstem & $3,-26,-15$ & 73 & .000005 \\
\hline p32 & Posterior cingulate & $1,-30,30$ & 61 & .000048 \\
\hline p32 & BA 40/39 & $44,-50,45$ & 61 & .000027 \\
\hline BA 9 & Intraparietal sulcus & $-30,-72,32$ & 69 & .000001 \\
\hline d32 & Occipital & $23,-91,20$ & 82 & .000001 \\
\hline \multicolumn{5}{|l|}{ MD Disease } \\
\hline 47/12 (OFC) & Inferior temporal & $48,-46,-18$ & 53 & .000001 \\
\hline 47/12 (OFC) & Occipital (RH) & $26,-92,20$ & 61 & .000003 \\
\hline 47/12 (OFC) & Occipital (LH) & $-25,-87,21$ & 90 & .000001 \\
\hline 47/12 (OFC) & Paracentral lobule & $2,-47,73$ & 62 & .000003 \\
\hline 47/12 (OFC) & Caudate body $(\mathrm{RH})$ & $12,3,15$ & 55 & .000014 \\
\hline al & Cerebellum & $29,-61,-36$ & 76 & .0000001 \\
\hline al & Fusiform (medial) & $34,-72,-18$ & 93 & .000006 \\
\hline al & Putamen & $-23,5,5$ & 68 & .000002 \\
\hline al & Caudate & $13,25,2$ & 61 & .000538 \\
\hline al & Occipital (LH) & $-34,-85,3$ & 54 & .000003 \\
\hline p32 & Precuneus (LH) & $-8,-72,33$ & 60 & .000000 \\
\hline p32 & Precuneus (RH) & $11,-71,41$ & 69 & .000130 \\
\hline p24 & Superior frontal gyrus & $-27,58,15$ & 72 & .000269 \\
\hline a24' & DLPFC & $-10,42,47$ & 68 & .000037 \\
\hline a24' & Paracentral lobule & $-7,-25,63$ & 58 & .000008 \\
\hline 11 (OFC) & Precuneus & $4,-66,52$ & 58 & .000929 \\
\hline
\end{tabular}

Anatomy labels are given according to automated anatomical labeling as seen in Tzourio-Mazoyer et al. (89). $p$ Values concern $F$ tests (see Supplement for all $p$ values).

a24', midcingulate field a24; al, anterior insula; BA, Brodmann area; d32, paracingulate region 32 dorsal; DLPFC, dorsolateral prefrontal cortex; LH, left hemisphere; MD, major depression group; MNI, Montreal Neurological Institute; OFC, orbitofrontal cortex; OMPFC, orbital and medial prefrontal cortex; p24, paracingulate region 24 pregenual; p32, paracingulate region 32 pregenual; $\mathrm{RH}$, right hemisphere.

\section{Correlation Analyses}

MD patients and $\mathrm{FH}$ participants share a set of FC indicators and show increased self-reported measures of depressive symptomatology compared with HC participants. Within neither group, however, did correlation analyses between the self-report measures of depressive symptomatology and the connectivity aberrations reveal significant relationships.

\section{DISCUSSION}

We examined changes in the FC of the OMPFC associated with MD. By starting from a previously established parcellation scheme (17), we delineated the specific subregions of OMPFC involved in the disease. By including a group of participants at familial risk for MD alongside MD patients and $\mathrm{HCs}$, we distinguished between the $\mathrm{FC}$ alterations that confer vulnerability to $\mathrm{MD}$ (i.e., $[\mathrm{MD}=\mathrm{FH}] \neq \mathrm{HC}$ ) and the $\mathrm{FC}$ correlates of the current MD episode (i.e., $M D \neq[F H=H C]$ ). Our results suggest that individuals with familial risk for MD, in the absence of clinically significant symptoms, share with patients aberrations in the FC of OMPFC fields that center on two foci, one in the dorsomedial prefrontal cortex and one in the anterior insula. Acute MD patients, in addition to these vulnerability changes, exhibit unique FC alterations originating from these same two foci and from one additional focus in the orbital frontal cortex. This suggests that neurobiologically MD starts off with confined predisposing FC abnormalities and progresses to a disease state with more extensive OMPFC alterations (Figure 3).

\section{FC in MD Vulnerability}

The first of the two foci of FC abnormality associated with MD vulnerability concerns an increased functional coupling between the anterior insula and the periaqueductal grey (PAG). The PAG is a brainstem control center for survival-related responses during stress and threat (32). Insula-PAG coupling strength has been shown to increase with perceived painfulness of a stimulus (33), experienced versus observed pain $(34,35)$, stressfulness of cognitive tasks (36), and proximity of a virtual predator (37). Against this background, the increased insula-PAG coupling observed here may suggest a proclivity in at-risk individuals to interpret anticipated events as more emotionally threatening or generally negative. In line with this, behavioral studies of vulnerability for MD show anticipatory affect biases, including increased threat reactivity $(38,39)$.

An affective bias hypothesis could also make sense of the second focus of vulnerability-related alterations in functional coupling between regions of the dorsal medial PFC and the posterior, "receptive" brain. The involved dorsal medial PFC region extends from the cingulate sulcus to the dorsal convexity of the SFG at around the intersection of the cognitive 
and affective part of the medial PFC (40). This region has dense anatomical connections to autonomic centers $(41,42)$ and has been implicated in the assessment salience and affective value of emotional information (43), conflict monitoring in the presence of emotional distractors (40,44-49), and in awareness and regulation of emotional responses (40,50-52). This affective bias hypothesis is further in agreement with behavioral characteristics observed in people with genetic MD susceptibility and those with remitted depression $(53,54)$, such as difficulty directing attention away from negative stimuli (54), reappraising (55), and suppressing negative distractors (56).

The altered FC of medial regions associated with this second focus fits this pattern. On the one hand, BA 9 and d32 showed changed coupling with the posterior intraparietal sulcus, which is part of the dorsal visual attention network (57). On the other hand, area p32 was uncoupled from the dorsal inferior parietal cortex implicated in the computation of priorities for attentional allocation $(58,59)$, the re-evaluation of conflicting choices between options $(60,61)$, and the reappraisal/suppression of emotion (55). Interestingly, the inferior parietal lobule has been found to respond to cognitive behavioral therapy $(62,63)$, a treatment aimed at modifying attentional biases and reinforcing emotion regulation strategies. Area p32 also lost functional coupling with the posterior cingulate cortex, which may relate to areas p32's role in memory consolidation (64). The dorsal posterior cingulate cortex has a mixed pattern of anatomical connectivity linking frontal default mode regions with parietal attention areas $(65,66)$ and is thought to balance internal and external attentional foci to retrieve and update behavioral strategies (67). In line with this, posterior cingulate cortex lesions result in deficits in implementing new strategies and changing cognitive set (67).

Taken together, the observed pattern of FC dysregulation between these OMPFC areas and the brainstem, dorsal attention areas, the inferior parietal lobule, and the posterior cingulate cortex might be the manifestation of a predisposition in MD-vulnerable individuals for anticipating or perceiving environmental events as threatening, painful, and overall negative. Increased occurrence of (perceived) negative experiences combined with a diminished ability to cognitively regulate the resulting emotional arousal might make at-risk individuals more prone to stress, chronic negative affect, and a dysregulated hypothalamic-pituitary-adrenal axis.

\section{FC in MD Disease}

In addition to the changes associated with MD vulnerability, patients with acute MD exhibited an extension of changes in the coupling of the two foci marking MD vulnerability (i.e., the anterior insula and the rostral cingulate) and an emergence of a new focus in the orbital frontal cortex. The cerebral targets of FC aberrations across these foci tend to aggregate in two functional zones. The first of these zones comprises areas of higher-order vision and attention in the posterior brain, which is already prominent in the vulnerability markers, while the second, in the SFG, seems specific to disease manifestation.

All three medial OMPFC foci show changed coupling with higher visual cortex, in both the ventral (loci $d$, e, and $j$ in
Figure 2) and the dorsal (loci $\mathrm{f}-\mathrm{i}$ in Figure 2) streams. The insular (al) and orbital (47/12) foci have changed coupling with the anterior ventral stream, responsible for the analysis and representation of visual objects and their identity (68). The orbital area 47/12 had changed coupling with the dorsal visual stream, namely the ventral intraparietal sulcus (69), already highlighted as an MD vulnerability indicator. The additional loss of coupling of this area with the contralateral oculomotor/ attentional part of the caudate nucleus further confirms the functional involvement of visual attentional processes. Finally, medial (area p32) and orbital foci (area 11 and 47/12) had changed coupling with parts of the nonlimbic precuneus also implicated in visual processing $(66,69)$. This part of the precuneus has previously been linked to MD, with patients showing increased node centrality (70) and abnormal activation to attentional targets and emotional distractors (71). This pattern of FC disturbances originating from all three OMFC foci of MD-related FC change strengthens the earlier suggestion that changed affective modulation of information processing is a core aspect of MD. In MD patients, the dorsal medial focus of FC change indicative of MD vulnerability gets an important extension into the cingulate gyrus (Figure 3), with two additional areas (p24 and a24') showing changed functional coupling. The cingulate extension spans the transition from the anterior to the midcingulate section of the cingulate cortex (72), with a24' being the rostral part of the midcingulate cortex, including the rostral cingulate motor area in the cingulate sulcus. This, together with the action selection/monitoring function attributed to the midcingulate cortex (73), might explain the changed coupling of a24' with the motor-related paracentral gyrus. Both of these areas show changed functional coupling with the SFG. The function of this part of SFG is not well studied, but it shows consistent functional coupling with nodes of the default mode network (18,74-76). Moreover, introspective tasks increase activity specifically in this part of SFG, with activity extending medially into BA 32 (77), while damage to SFG and BA 32 correlates with impairment in reappraising the personal relevance of negative events (78). Interestingly, this part of the SFG has also been implicated in expressions of positive affect, such as laughter (79) and humor (80), which are important for self-centered reappraisal.

\section{Limitations}

While our results provide the first insightful dissociation of FC abnormalities in MD vulnerability and disease, replication is needed, particularly given the heterogeneity of clinical populations. Although we corrected rigorously for medication and Axis I comorbidity effects, replication should ideally be sought in a large independent sample of unmedicated MD participants. Second, while the FC abnormalities described here reflect significant group differences related to MD vulnerability and disease, we could not examine whether they are specific to MD. Future studies should examine whether these FC changes could differentiate between unipolar depression and other psychiatric syndromes. Lastly, our focus on OMPFC prevents drawing conclusions regarding other brain areas. For instance, executive dysfunctions often manifest in MD, which would predict FC abnormalities associated with more cognition-centered networks. 


\section{Conclusions}

The current study systematically delineated FC alterations of cortical units in the OMPFC in MD using a published parcellation map. This enabled a more fine-grained localization of the pathogenetically relevant subregions within the affective cortex. We also used conjunction analyses on groups of $\mathrm{HCs}$, MD-susceptible individuals, and patients during MD episodes and dissociated the patterns of connectivity aberrations in MD vulnerability from aberrations in MD manifestation. Our results complement previous evidence that the OMPFC, anatomically and functionally linked to autonomic and affective centers, shows connectivity aberrations in both MD states. Moreover, we provide evidence that these functional aberrations concern primarily the relationship of specific OMPFC subparts and the posterior receptive cortex and various regions specifically within the dorsal and ventral visual processing streams. This in line with the increasingly recognized relationship between emotion and visual perception: visual stimuli and experiences trigger and shape emotions and affect, as well as being shaped by mood states $(81,82)$.

Further, our results highlight two OMPFC regions-both of which are implicated in MD vulnerability and disease manifestation-as being central to depression's pathophysiology: the anterior insula and the rostral anterior cingulate area p32. Both areas have been previously shown to have altered activity and connectivity in MD (83-86). More importantly, they are both central nodes within two extended neural networks, the salience network and the default mode network, that have also been implicated in MD $(87,88)$. We provide evidence that the connectivity of these central nodes or hubs is altered not only in the MD disease state but also long before any clinical symptoms appear in individuals with familial MD vulnerability.

\section{ACKNOWLEDGMENTS AND DISCLOSURES}

This work was supported by the Netherlands Initiative Brain and Cognition, a part of the Netherlands Organization for Scientific Research Grant No. 056-13-012 (to EATE) and National Institutes of Health Grant No. 5P30GM103328 (to GR).

The authors report no biomedical financial interests or potential conflicts of interest.

\section{ARTICLE INFORMATION}

From the Department of Neuropsychology and Psychopharmacology (ZS, EATE, FP, JGR, PS), Maastricht University, Maastricht, and the Department of Anatomy and Neuroscience (HBMU), VU University Medical Center, Amsterdam, The Netherlands; and the Department of Psychiatry and Human Behavior (GR), University of Mississippi Medical Center, Jackson, Mississippi.

Address correspondence to Zoe Samara, Ph.D., Psychiatry \& Behavioral Sciences, School of Medicine, Stanford University, 401 Quarry Road, Stanford, CA 94305-5717; E-mail: zsamara@stanford.edu.

Received Jul 5, 2017; revised Jan 12, 2018; accepted Jan 16, 2018.

Supplementary material cited in this article is available online at https:// doi.org/10.1016/j.bpsc.2018.01.004.

\section{REFERENCES}

1. American Psychiatric Association (1994): Diagnostic and Statistical Manual of Mental Disorders, 4th ed. Washington, DC: American Psychiatric Press.

2. Downar J, Daskalakis ZJ (2013): New targets for rTMS in depression: A review of convergent evidence. Brain Stimul 6:231-240.
3. Riva-Posse P, Holtzheimer PE, Garlow SJ, Mayberg HS (2013): Practical considerations in the development and refinement of subcallosal cingulate white matter deep brain stimulation for treatmentresistant depression. World Neurosurg 80:25-34.

4. Price JL, Drevets WC (2010): Neurocircuitry of mood disorders. Neuropsychopharmacology 35:192-216.

5. Pizzagalli DA (2011): Frontocingulate dysfunction in depression: Toward biomarkers of treatment response. Neuropsychopharmacology 36:183-206.

6. Hamani C, Mayberg H, Stone S, Laxton A, Haber S, Lozano AM (2010): The subcallosal cingulate gyrus in the context of major depression. Biol Psychiatry 69:301-308.

7. Price JL, Drevets WC (2012): Neural circuits underlying the pathophysiology of mood disorders. Trends Cogn Sci 16:61-71.

8. Greicius MD, Flores BH, Menon V, Glover GH, Solvason HB, Kenna H, et al. (2007): Resting-state functional connectivity in major depression: Abnormally increased contributions from subgenual cingulate cortex and thalamus. Biol Psychiatry 62:429-437.

9. Guo H, Cheng C, Cao X, Xiang J, Chen J, Zhang K (2014): Restingstate functional connectivity abnormalities in first-onset unmedicated depression. Neural Regen Res 9:153-163.

10. Sheline YI, Price JL, Yan Z, Mintun MA (2010): Resting-state functional $\mathrm{MRI}$ in depression unmasks increased connectivity between networks via the dorsal nexus. Proc Natl Acad Sci U S A 107:11020-11025.

11. Sundermann B, Beverborg MO, Pfleiderer B (2014): Toward literaturebased feature selection for diagnostic classification: A meta-analysis of resting-state fMRI in depression. Front Hum Neurosci 8:692.

12. Wang L, Hermens DF, Hickie IB, Lagopoulos J (2012): A systematic review of resting-state functional-MRI studies in major depression. J Affect Disord 142:6-12.

13. Mulders PC, van Eijndhoven PF, Schene AH, Beckmann CF, Tendolkar I (2015): Resting state functional connectivity in major depressive disorder: A review. Neurosci Biobehav Rev 56:330-344.

14. Eickhoff SB, Thirion B, Varoquaux G, Bzdok D (2015): Connectivitybased parcellation: Critique and implications. Hum Brain Mapp 36:4771-4792.

15. Krubitzer $L$ (1995): The organization of neocortex in mammals: Are species differences really so different? Trends Neurosci 18: 408-417.

16. Passingham RE, Stephan KE, Kötter R (2002): The anatomical basis of functional localization in the cortex. Nat Rev Neurosci 3:606-616.

17. Samara Z, Evers EAT, Goulas A, Uylings BM, Rajkowska G, Ramaekers JG, et al. (2017): Human orbital and anterior medial prefrontal cortex: Intrinsic connectivity parcellation and functional organization. Brain Struct Funct 17:1378-1382.

18. Girvan M, Newman MEJ (2002): Community structure in social and biological networks. Proc Natl Acad Sci U S A 99:7821-7826.

19. Rubinov M, Sporns $O$ (2010): Complex network measures of brain connectivity: Uses and interpretations. Neuroimage 52:1059-1069.

20. Barnes KA, Cohen AL, Power JD, Nelson SM, Dosenbach YBL, Miezin FM, et al. (2010): Identifying basal ganglia divisions in individuals using resting-state functional connectivity MRI. Front Syst Neurosci 4:18.

21. Goulas A, Uylings HBM, Stiers P (2012): Unravelling the intrinsic functional organization of the human lateral frontal cortex: A parcellation scheme based on resting state fMRI. J Neurosci 32:1023810252.

22. Barbas H, Pandya DN (1989): Architecture and intrinsic connections of the prefrontal cortex in the rhesus monkey. J Comp Neurol 286:353-375.

23. Ongür D, Price JL (2000): The organization of networks within the orbital and medial prefrontal cortex of rats, monkeys and humans. Cereb Cortex 10:206-219.

24. Yeterian EH, Pandya DN, Tomaiuolo F, Petrides M (2012): The cortical connectivity of the prefrontal cortex in the monkey brain. Cortex 48:58-81.

25. Chen J, Zhou C, Wu B, Wang Y, Li Q, Wei Y, et al. (2013): Left versus right repetitive transcranial magnetic stimulation in treating major depression: A meta-analysis of randomised controlled trials. Psychiatry Res 210:1260-1264. 
26. Beck AT, Steer RA, Ball R, Ranieri W (1996): Comparison of Beck Depression Inventories-IA and -II in psychiatric outpatients. J Pers Assess 67:588-597.

27. Derogatis L, Melisaratos N (1983): The Brief Symptom Inventory: An introductory report. Psychol Med 13:595-605.

28. Rush AJ, Trivedi MH, Ibrahim HM, Carmody TJ, Arnow B, Klein DN (2003): The 16-item Quick Inventory of Depressive Symptomatology (QIDS) Clinician Rating (QIDS-C) and Self-Report (QIDS-SR): A psychometric evaluation in patients with chronic major depression. Biol Psychiatry 54:573-583.

29. Raven J, Raven JC, Court JH (2003): Manual for Raven's Progressive Matrices and Vocabulary Scales. Section 1: General Overview. San Antonio: Harcourt Assessment.

30. Van Dijk KRA, Sabuncu MR, Buckner RL (2012): The influence of head motion on intrinsic functional connectivity MRI. Neuroimage 59:431-438.

31. Power JD, Barnes KA, Snyder AZ, Schlaggar BL, Petersen SE (2012): Spurious but systematic correlations in functional connectivity MR networks arise from subject motion. Neuroimage 59:2142-2154.

32. Bandler R, Keay KA, Floyd N, Price J (2000): Central circuits mediating patterned autonomic activity during active vs. passive emotional coping. Brain Res Bull 53:95-104.

33. Ploner M, Lee MC, Wiech K, Bingel U, Tracey I (2010): Prestimulus functional connectivity determines pain perception in humans. Proc Natl Acad Sci U S A 107:355-360.

34. Lamm C, Meltzoff AN, Decety J (2010): How do we empathize with someone who is not like us? A functional magnetic resonance imaging study. J Cogn Neurosci 22:362-376.

35. Zaki J, Ochsner KN, Hanelin J, Wager TD, Mackey SC (2007): Different circuits for different pain: Patterns of functional connectivity reveal distinct networks for processing pain in self and others. Soc Neurosci 2:276-291.

36. Linnman C, Moulton EA, Barmettler G, Becerra L, Borsook D (2013): Neuroimaging of the periaqueductal gray: State of the field. Neuroimage 60:505-522.

37. Mobbs D, Petrovic P, Marchant JL, Hassabis D, Weiskopf N, Seymour B, et al. (2007): When fear is near: Threat imminence elicits prefrontal-periaqueductal gray shifts in humans. Science 317:10791083.

38. Dearing KF, Gotlib IH (2009): Interpretation of ambiguous information in girls at risk for depression. J Abnorm Child Psychol 37:79-91.

39. Grupe DW, Nitschke JB (2013): Uncertainty and anticipation in anxiety: An integrated neurobiological and psychological perspective. Nat Rev Neurosci 14:488-501.

40. Bush G, Luu P, Posner MI (2000): Cognitive and emotional influences in anterior cingulate cortex. Trends Cogn Sci 4:215-222.

41. Porro CA, Cettolo V, Francescato MP, Baraldi P (2003): Functional activity mapping of the mesial hemispheric wall during anticipation of pain. Neuroimage 19:1738-1747.

42. Critchley HD (2005): Neural mechanisms of autonomic, affective, and cognitive integration. J Comp Neurol 493:154-166.

43. Grabenhorst F, Rolls ET, Parris BA (2008): From affective value to decision-making in the prefrontal cortex. Eur J Neurosci 28(9):19301939.

44. Etkin A, Egner T, Peraza DM, Kandel ER, Hirsch J (2006): Resolving emotional conflict: A role for the rostral anterior cingulate cortex in modulating activity in the amygdala. Neuron 51:871-882.

45. Foland-Ross LC, Gotlib IH (2012): Cognitive and neural aspects of information processing in major depressive disorder: An integrative perspective. Front Psychol 3:489.

46. Roy M, Shohamy D, Wager TD (2012): Ventromedial prefrontalsubcortical systems and the generation of affective meaning. Trends Cogn Sci 16:147-156.

47. Egner T, Etkin A, Gale S, Hirsch J (2008): Dissociable neural systems resolve conflict from emotional versus nonemotional distracters. Cereb Cortex 18:1475-1484.

48. Salomons TV, Johnstone T, Backonja M-M, Davidson RJ (2004): Perceived controllability modulates the neural response to pain. J Neurosci 24:7199-7203.
49. Rey G, Desseilles M, Favre S, Dayer A, Piguet C, Aubry J-M, Vuilleumier P (2014): Modulation of brain response to emotional conflict as a function of current mood in bipolar disorder: Preliminary findings from a follow-up state-based fMRI study. Psychiatry Res 223:84-93.

50. Herwig $U$, Kaffenberger T, Baumgartner T, Jäncke L (2007): Neural correlates of a "pessimistic" attitude when anticipating events of unknown emotional valence. Neuroimage 34:848-858.

51. Mayberg H (2003): Modulating dysfunctional limbic-cortical circuits in depression: Towards development of brain-based algorithms for diagnosis and optimised treatment. Br Med Bull 65:193-207.

52. Piefke M, Weiss PH, Zilles K, Markowitsch HJ, Fink GR (2003): Differential remoteness and emotional tone modulate the neural correlates of autobiographical memory. Brain 126:650-668.

53. Foland-Ross LC, Hardin MG, Gotlib IH (2013): Neurobiologica markers of familial risk for depression. Curr Top Behav Neurosci 14:181-206.

54. Browning M, Holmes EA, Charles M, Cowen PJ, Harmer CJ (2012): Using attentional bias modification as a cognitive vaccine against depression. Biol Psychiatry 72:572-579.

55. Viviani R (2013): Emotion regulation, attention to emotion, and the ventral attentional network. Front Hum Neurosci 7:746.

56. Kerr N, Scott J, Phillips ML (2005): Patterns of attentional deficits and emotional bias in bipolar and major depressive disorder. $\mathrm{Br} \mathrm{J}$ Clinical Psychol 44:343-356.

57. Corbetta M, Shulman GL (2002): Control of goal-directed and stimulus-driven attention in the brain. Nat Rev Neurosci 3:201-215.

58. Caspers S, Eickhoff SB, Rick T, von Kapri A, Kuhlen T, Huang R, et al. (2011): Probabilistic fibre tract analysis of cytoarchitectonically defined human inferior parietal lobule areas reveals similarities to macaques. Neuroimage 58:362-380.

59. Caspers S, Schleicher A, Bacha-Trams M, Palomero-Gallagher N, Amunts K, Zilles K (2013): Organization of the human inferior parietal lobule based on receptor architectonics. Cereb Cortex 23:615-628.

60. Kim C, Chung C, Kim J (2010): Multiple cognitive control mechanisms associated with the nature of conflict. Neurosci Lett 476:156-160.

61. Mars RB, Jbabdi S, Sallet J, O’Reilly JX, Croxson PL, Olivier E, et al. (2011): Diffusion-weighted imaging tractography-based parcellation of the human parietal cortex and comparison with human and macaque resting-state functional connectivity. J Neurosci 31:4087-4100.

62. Goldapple K, Segal Z, Garson C, Lau M, Bieling P, Kennedy S, et al. (2004): Modulation of cortical-limbic pathways in major depression: Treatment-specific effects of cognitive behavior therapy. Arch Gen Psychiatry 61:34-41.

63. Fu CHY, Williams SCR, Cleare AJ, Scott J, Mitterschiffthaler MT, Walsh ND, et al. (2008): Neural responses to sad facial expressions in major depression following cognitive behavioral therapy. Biol Psychiatry 64:505-512.

64. Nieuwenhuis IL, Takashima A (2011): The role of the ventromedia prefrontal cortex in memory consolidation. Behav Brain Res 218 325-334.

65. Vincent JL, Snyder AZ, Fox MD, Shannon BJ, Andrews JR Raichle ME, et al. (2006): Coherent spontaneous activity identifies a hippocampal-parietal memory network. J Neurophysiol 96 3517-3531.

66. Margulies DS, Vincent JL, Kelly C, Lohmann G, Uddin LQ, Biswal BB, et al. (2009): Precuneus shares intrinsic functional architecture in humans and monkeys. Proc Natl Acad Sci U S A 106:20069-20074.

67. Pearson JM, Heilbronner SR, Barack DL, Hayden BY, Platt ML (2012): Posterior cingulate cortex: Adapting behavior to a changing environment. Trends Cogn Sci 15:143-151.

68. Kravitz DJ, Saleem KS, Baker Cl, Ungerleider LG, Mishkin M (2013): The ventral visual pathway: An expanded neural framework for the processing of object quality. Trends Cogn Sci 17:26-49.

69. Stiers P, Peeters R, Lagae L, Van Hecke P, Sunaert S (2006): Mapping multiple visual areas in the human brain with a short $\mathrm{fMRI}$ sequence. Neuroimage 29:74-89. 
70. Zhang J, Wang J, Wu Q, Kuang W, Huang X, He Y, et al. (2011): Disrupted brain connectivity networks in drug-naive, first-episode major depressive disorder. Biol Psychiatry 70:334-342.

71. Wang L, LaBar KS, Smoski M, Rosenthal MZ, Dolcos F, Lynch TR, et al. (2008): Prefrontal mechanisms for executive control over emotional distraction are altered in major depression. Psychiatry Res 163:143-155.

72. Palomero-Gallagher N, Vogt BA, Schleicher A, Mayberg HS, Zilles K (2009): Receptor architecture of human cingulate cortex: Evaluation of the four-region neurobiological model. Hum Brain Mapp 30:2336-2355.

73. Rushworth MFS, Walton ME, Kennerley SW, Bannerman DM (2004): Action sets and decisions in the medial frontal cortex. Trends Cogn Sci 8:410-417.

74. Fox MD, Snyder AZ, Vincent JL, Corbetta M, Van Essen DC, Raichle ME (2005): The human brain is intrinsically organized into dynamic, anticorrelated functional networks. Proc Natl Acad Sci U S A 102:9673-9678.

75. Li B, Liu L, Friston KJ, Shen H, Wang L, Zeng LL, et al. (2013): A treatment-resistant default mode subnetwork in major depression. Biol Psychiatry 74:48-54.

76. Yeo BT, Krienen FM, Sepulcre J, Sabuncu MR, Lashkari D, Hollinshead M, et al. (2011): The organization of the human cerebral cortex estimated by functional connectivity. J Neurophysiol 106:1125-1165.

77. Goldberg II, Harel M, Malach R (2006): When the brain loses its self: Prefrontal inactivation during sensorimotor processing. Neuron 50:329-339.

78. Falquez R, Couto B, Ibanez A, Freitag MT, Berger M, Arens EA, et al. (2014): Detaching from the negative by reappraisal: The role of right superior frontal gyrus (BA9/32). Front Behav Neurosci 8:165.

79. Fried I, Wilson C, MacDonald K, Behnke E (1998): Electric current stimulates laughter. Nature 391:650.

80. Campbell DW, Wallace MG, Modirrousta M, Polimeni JO, McKeen NA, Reiss JP (2015): The neural basis of humour comprehension and humour appreciation: The roles of the temporoparietal junction and superior frontal gyrus. Neuropsychologia 79:10-20.

81. Zadra JR, Clore GL (2011): Emotion and perception: The role of affective information. Wiley Interdiscip Rev Cogn Sci 2:676-685.

82. Zhang X, Zuo B, Erskine K, Hu T (2016): Feeling light or dark? Emotions affect perception of brightness. J Environ Psychol 47:107-111.

83. Horn DI, Yu C, Steiner J, Buchmann J, Kaufmann J, Osoba A, et al. (2010): Glutamatergic and resting-state functional connectivity correlates of severity in major depression - the role of pregenual anterior cingulate cortex and anterior insula. Front Syst Neurosci 4:33.

84. Pezawas L, Meyer-Lindenberg A, Drabant EM, Verchinski BA, Munoz KE, Kolachana BS, et al. (2005): 5-HTTLPR polymorphism impacts human cingulate-amygdala interactions: A genetic susceptibility mechanism for depression. Nat Neurosci 8:828-834.

85. Sliz D, Hayley S (2012): Major depressive disorder and alterations in insular cortical activity: A review of current functional magnetic imaging research. Front Hum Neurosci 6:323.

86. McGrath CL, Kelley ME, Holtzheimer PE, Dunlop BW, Craighead WE, Franco AR, et al. (2013): Toward a neuroimaging treatment selection biomarker for major depressive disorder. JAMA Psychiatry 70: 821-829.

87. Kaiser RH, Andrews-Hanna JR, Wager TD, Pizzagalli DA (2015): Large-scale network dysfunction in major depressive disorder: Metaanalysis of resting-state functional connectivity. JAMA Psychiatry 72:603-611.

88. Manoliu A, Meng C, Brandl F, Doll A, Tahmasian M, Scherr M, et al. (2013): Insular dysfunction within the salience network is associated with severity of symptoms and aberrant inter-network connectivity in major depressive disorder. Front Hum Neurosci 7:930.

89. Tzourio-Mazoyer N, Landeau B, Papathanassiou D, Crivello F, Etard O, Delcroix N, et al. (2002): Automated anatomical labeling of activations in SPM using a macroscopic anatomical parcellation of the MNI MRI single-subject brain. Neuroimage 15:273-289. 